\title{
An Overview of the Potential Effects of Melatonin Supplementation on Athletic Performance
}

\author{
Amine Souissi (iD) ${ }^{1}$ and Ismail Dergaa (iD) ${ }^{2, *}$ \\ ${ }^{1}$ Heart Failure (LR12SP09) Research Laboratory, Farhat HACHED Hospital, University of Sousse, Sousse, Tunisia \\ ${ }^{2}$ Primary Health Care Corporation (PHCC), Doha, Qatar \\ "Corresponding author: Primary Health Care Corporation (PHCC), Doha, Qatar. Email: phd.dergaa@gmail.com \\ Received 2022 January 02; Accepted 2022 January 25.
}

\begin{abstract}
Background: Melatonin is a pineal gland hormone. Melatonin is often used to treat insomnia and enhance sleep quality in a range of situations, including jet lag. However, the benefit and safety profile of daytime melatonin dosing prior to exercise are unknown and warrant additional exploration.

Objectives: We aimed to give (i) a brief overview of the beneficial effects of exogenous melatonin administration on sports performance and (ii) some recommendations for acute use of melatonin with a special focus on humans' physical activity and athletic performance.

Methods: To ascertain the effect of exogenous melatonin administration on humans, a systematic review of the literature was undertaken using PubMed, ScienceDirect, Medline, Google Scholar, and Scopus. Numerous studies in animals have demonstrated the positive impact of melatonin treatment during physical exercise. However, uncertainty remains regarding melatonin's effect on human exercise physiology. Therefore, the present review focuses almost entirely on data obtained from humans.

Results: The gathered data indicate that consuming melatonin at night improves sleep quality. In terms of physical activity and sports performance, past research has demonstrated that melatonin administration has a good effect on decreasing oxidative stress and inflammation induced by exercise and providing additional protection for skeletal muscle against exercise-induced oxidative damage in humans. However, when taken at bedtime, melatonin may have an unfavourable influence on performance during acute and strenuous exercise.

Conclusions: Exogenous melatonin administration prior to exercise shows significant chronobiotic, antioxidant, antiadrenergic, and hypothermic effects and may represent a fascinating potential weight loss method. However, consuming a high amount of melatonin (6 mg) 50 minutes prior to commencing exercise is not recommended because it may interfere with the physiological reactions to physical activity. Melatonin-related adverse effects were mainly transient and were associated with daytime doses. Melatonin should therefore be provided at night whenever possible.
\end{abstract}

Keywords: Antioxidant Status, Free Radicals, Cardiac Function, Physical Performance, Sleep, Sports

\section{Background}

Melatonin (N-acetyl-5-methoxytryptamine) is a hormone produced by the pineal gland, which is located near the hypothalamus in the centre of the brain. Melatonin secretion follows a diurnal cycle, with the lowest temperature levels occurring in the early morning following the highest melatonin level and the highest temperature levels occurring in the late evening following the lowest melatonin level $(1,2)$. Melatonin levels may peak 30 times greater than normal during the daytime early in the morning, when the body temperature is at its lowest (3-6). Additionally, it was recently found that melatonin release may be lunar-dependent, with a peak recorded around the full moon versus the new moon $(7,8)$.

Melatonin is an extremely powerful antioxidant (9). Its activities have been studied in medical and sports science disciplines. Melatonin is a key regulator of circadian rhythms, sleep, body temperature, mood, reproduction, tumour growth, and aging (10). Furthermore, melatonin regulates critical physiological functions such as anxiety, immune function, and heart function (11-15). Melatonin's physiological and therapeutic significance, particularly in relation to sleep, has been recognized for decades $(16,17)$. While there is mixed evidence about melatonin's ergogenic effect, its antioxidant properties undoubtedly contribute to its preventive effects against exercise-induced oxidative stress $(18,19)$. Melatonin may 
also have an effect on physical performance, implying that exercise and melatonin production are mutually advantageous (20). When dynamic workouts such as running, cycling, and swimming are conducted at an extreme level with an anaerobic metabolism, they result in the formation of free radicals (21). As a result, research into the antioxidant effects on exercise-induced heart injury has become a focus of interest for athletes, coaches, exercise physiologists, and free radical biologists. Numerous studies have demonstrated the potential benefits of antioxidant (including melatonin) consumption, either through food or supplementation, in reducing exercise-induced oxidative stress $(22,23)$. However, there are still concerns and reservations about the role of melatonin in exercise physiology, despite the fact that melatonin's physiology has been thoroughly investigated in animals. For years, evidence collected from animals has been generalized without careful review to humans. As a result, this review will concentrate almost solely on human data defining the effects of exogenous melatonin administration on health, with a particular emphasis on physical performance.

\section{Objectives}

The purpose of this study was to (i) provide a comprehensive summary of exogenous melatonin's beneficial effects on health and (ii) summarize the effect of exogenous melatonin on physical and fitness performance.

\section{The Beneficial Effect of Melatonin Supplementation on Sports Performance}

Sleep and recovery are key components of an athlete's health and performance enhancement as a result of training programs. According to previous research, athletes frequently use sleep-enhancing supplements, and melatonin is one of the most frequently used due to its additional beneficial effects on the body, including its antioxidant properties that protect muscles from oxidative stress and its performance-enhancing properties (24).

In men, adults, and the elderly, exogenous melatonin is effective as an antioxidant and anti-inflammatory supplement for extending muscle strength and adaptability during strenuous activity $(18,25,26)$. Supplementation with melatonin prior to and during exercise enhances glucose resistance and antioxidant status in a range of settings, including preparatory training, soccer training camps, resistance training, and highly trained athletes (19, 27-29).

Along with its anti-radical and antioxidant characteristics, the hormone can transform glucose metabolism from anaerobic glycolysis to aerobic mitochondrial oxidative phosphorylation for ATP synthesis. Pre-exercise melatonin administration enhances glucose utilization as a substrate energy source. Extended activity depletes glucose and fatty acids, resulting in a decrease in muscle and liver glycogen stores. Consumption of melatonin before endurance exercise has been shown to protect muscle glycogen stores against a chemical that impairs exercise performance (24).

Exogenous melatonin's effect on physical performance is still controversial and contentious. According to LópezFlores et al. (30), melatonin supplementation may be beneficial or unsuccessful depending on the type of activity. Due to the fact that melatonin secretion is reduced during low-intensity activity but elevated during high-intensity exercise, the effects of exogenous melatonin supplementation are unique and warrant additional investigation.

\section{Effect of Daytime Ingestion of Melatonin on Athletic Performance}

Several studies (31-33) have documented melatonin's effect on sleep and the physiological processes that accompany it, such as temperature and circadian rhythm regulation. Additionally, its antioxidant properties, antiaging properties, and immune system regulation have been studied. Melatonin is primarily used as a pharmaceutical supplement to aid in sleep quality improvement. Thus, favourable effects on performance must outweigh potential deleterious effects associated with central nervous system deficiency (34) because a 5-mg dose of melatonin may be sufficient to induce sleepiness.

Indeed, diurnal melatonin ingestion in young healthy men has been shown to cause sleepiness, weariness, alertness deprivation, loss of balance, and poor coordination (35). As a result, considerable debate exists, which may be explained by the dose size, the frequency of supplementation (acute or chronic), the time of administration, and the protocol design. Samuels (36) found no negative impacts on athletes' judgments of their health when they were asked about their headaches, insomnia, hyperactivity, irritability, sickness, constipation, stomach cramps, tiredness, numbness and tingling, sweating, and feelings of hunger. Additionally, because to the drop in body temperature caused by melatonin, its usage has been tested on sports performance in high temperatures. Certain research has examined melatonin's hypothermic effect, revealing a $0.2^{\circ} \mathrm{C}$ reduction in body temperature following $6 \mathrm{mg}$ of melatonin ingestion (37). While exogenous melatonin does have a hypothermic impact, it is unknown whether this effect benefits any aspect of athletic performance (38). 


\section{Effect of Daytime Ingestion of Melatonin on Phys- iological Responses to Submaximal Exercise-induced Hyperthermia}

In humans, little attention has been paid to melatonin's potential ergogenic benefits on exercise performance (38). A number of recent experimental experiments have indicated that exercise may be harmed by achieving a high core temperature $(39,40)$. Prior to activity, strategies that seek to reduce body temperature provide a bigger buffer before these key limiting temperatures are reached, which may result in performance benefits. Melatonin was once thought to act as a "cooling pill" by delaying the onset of a fever during exercise, hence improving endurance performance. Similarly, Souissi et al. $(37,41)$ observed that a single $6 \mathrm{mg}$ dose of melatonin lowered resting body temperature by $0.2^{\circ} \mathrm{C}$, which is consistent with Marrin et al. (42). Melatonin, on the other hand, had no effect on the increase in body temperature during exercise (41). The findings show that acute melatonin injection before to endurance exercise has no hypothermic effect during exercise, which is consistent with McLellan et al. (43) and Brandenberger et al. (44) findings that melatonin has no hypothermic effect during exercise.

Our group's investigations $(37,41,45,46)$ revealed intriguing and unexpected findings regarding the physiological (heart rate and rectal temperature) and biological (sodium, potassium, hemoglobin, hematocrit, lactate, creatinine, uric acid, and parathyroid hormone) responses to exercise in healthy individuals with low oxidative stress. For the first time, a single dose ( $>5 \mathrm{mg}$ ) of melatonin was used. Our group reported that sweating, cardiovascular, and renal function may be impacted $(37,41,45,46)$. According to Souissi et al. (37), melatonin may impair the exercise-induced sweating response. The decrease in perspiration rate following melatonin administration was attributed to nitric oxide synthase inhibition (47). Otherwise, melatonin has been shown to lower the heart rate during exercise (41). However, the mechanism by which melatonin impacts the heart rate response to exercise remains unknown.

Melatonin appears to reduce heart rate by inhibiting sympathetic tone (48), catecholamine levels (49), and nitric oxide generation $(37,41,50,51)$. According to Souissi et al. (46), melatonin lowers alertness and increases the exercise-induced increase in parathyroid hormone while maintaining a normal glomerular filtration rate. In agreement with Souissi et al. (46), Cook et al. (52) hypothesize that exogenous melatonin can change vascular blood flow in humans by increasing sympathetic output to the kidney, hence mediating renal vasoconstriction. However, it is unknown whether melatonin-induced free radical in- hibition contributes to renal vasoconstriction, given that the only studies examining melatonin's influence on renal function used animal models. Indeed, Aydogdu et al. (53) observed that exogenous melatonin decreases nitric oxide levels in rats, resulting in acute renal failure. The administration of a large dose ( $6 \mathrm{mg}$ ) of melatonin before exercise may impair renal function due to its vasoconstrictor action $(46,52)$.

In summary, our group concluded that administering a high dose of melatonin ( $>5 \mathrm{mg}$ ) prior to exercise (50 $\mathrm{min}$ ) is not recommended for reducing the increase in core temperature during continuous exercise or improving endurance performance in healthy humans. In fact, administering a high dose of melatonin prior to exercise may impair renal function due to its vasoconstrictor effect on the kidneys. By and large, excessive antioxidants have little beneficial effect on healthy people. Additionally, excessive antioxidants may have pro-oxidant effects by altering the redox balance $(41,54)$. The work by Souissi et al. $(37,41)$ is consistent with previous research demonstrating a modification in blood flow (vascular control) during dynamic exercise in healthy young adults following oral antioxidant therapy $(55,56)$. Furthermore, a significant dose of melatonin administered during the day (at bedtime) has been shown to elicit minor narcotic effects (46) and sleepiness and other adverse effects $(37,41,45,46)$, and so is not recommended (57). When consumed during the day, melatonin can throw off the body's circadian clock, resulting in an increase in oxidative stress (57).

\section{How Much Acute Melatonin Ingestion Should Be Used to Enhance Endurance Performance?}

Prolonged exercise increases the heart rate $(41,58)$, amplifying the mechanical forces of blood flow on the vascular wall, such as shear stress, pressure, and cyclic strain (58, 59). Shear stress has been observed to increase endothelial superoxide production in conductance arteries (60). Prolonged, sustained high levels of shear stress, such as those encountered during exercise due to increased cardiac output, have been demonstrated to enhance the formation of nitric oxide, hydrogen peroxide, and vascular superoxide $(58,61)$.

When excessive levels of nitric oxide are created, it reacts with oxygen to make peroxynitrite, an unstable molecule that degrades into deadly hydroxyl radicals. Increased superoxide and nitric oxide production undermines antioxidant defenses $(62,63)$. Additionally, prolonged and severe exercise promotes inflammation as a result of the increased production of free radicals, reactive oxygen and nitrogen species, and probable oxidative muscle injury $(62,63)$. 
Thus, prolonged periods of exercise (or intense activity) result in an increase in vascular oxidative stress, which is regarded a pathogenic component that contributes to heart exhaustion and even renal inflammation (58, 59, 64). We hypothesize that administering a low dose of melatonin just before or during exercise may improve cardiovascular and renal function by reducing vascular oxidative stress and peroxynitrite production in the endothelium, which increases nitric oxide bioavailability, decreases inflammation, promotes vasorelaxation, and improves cardiovascular performance (58). Additionally, oxidative stress is exacerbated during the aging process (65), suggesting that melatonin may be especially advantageous for older individuals and those with chronic conditions.

\section{Adverse Occurrences Related to Oral Melatonin Dos- ing}

Although melatonin has numerous good effects (23, $66)$, there have been some isolated reports of a few unpleasant side effects (e.g., a modest increase in blood pressure due to nitric oxide synthase downregulation) (37, 45, $46,50,51)$. Notably, it is well recognized that diurnal melatonin ingestion in young healthy men might result in sleepiness, weariness, alertness deficiency, loss of balance, and poor coordination $(35,46)$.

Ghattassi et al. (67) examined the effects of melatonin administration of $5 \mathrm{mg}$ or $8 \mathrm{mg} 30$ minutes prior to physical activity trials. They found no change in performance between the placebo and $5 \mathrm{mg}$ melatonin but discovered significant adverse effects on subjects' performance following $8 \mathrm{mg}$ melatonin administration. Indeed, exogenous melatonin appears to have a dose-dependent influence on blood pressure. Melatonin behaves variably in the body depending on the dose consumed $(52,68,69)$. Animal studies confirm a dose-response relationship between melatonin concentration and vascular alterations $(70,71)$, adrenal nerve activity (72), and hormonal secretion responses (73).

Numerous investigations have revealed detrimental impacts on performance indicators in professional athletes (32, 67), and healthy volunteers (37, 45, 46, 74-77). When $5 \mathrm{mg}$ of melatonin was administered prior to a driving test, it was discovered that it had a substantial effect on selective attention, despite the fact that all other parameters were within the usual range (76). No further impacts on driving performance indicators were observed when melatonin was administered versus placebo in this trial (76). In another study, melatonin had a detrimental effect on reaction time during a four-choice visual reaction time test administered two hours following a daytime dose of
$240 \mathrm{mg}$ of melatonin or a placebo (74). Notably, while reaction time fell in this test, accuracy increased, and melatonin had no effect on the results of four other tests assessing performance, visual sensitivity, and memory (74). When compared to placebo, visual tracking and reaction speed were likewise impaired following a $5 \mathrm{mg}$ daytime dose of melatonin (75). The negative effects on visual tracking and reaction time were confirmed in a subsequent investigation, as were detrimental effects on spatial memory and vigilance tests (77). Some other studies found that a lower daytime dose (2-2.4mg) reduced visual reaction time while leaving attention, alertness, and cognitive processing unaltered (78).

The most commonly reported side effects include decreased psychomotor and cognitive performance, weariness, and excessive sleepiness, all of which are consistent with melatonin's long-established sedative and hypnotic qualities (79). These phenomena were mostly observed in studies in which melatonin was administered directly before psychomotor and neurocognitive function tests or during daylight hours, when endogenous melatonin activity is low (80). This suggests that melatonin should not be taken immediately prior to activities requiring a high degree of alertness to avoid such undesirable effects. Additionally, a large dose of melatonin should not be taken before prolonged endurance exercise ( $>30$ minutes), but rather at night whenever possible, in accordance with human biological circadian rhythms and previous scientific literature on melatonin for sleep problems (81).

In summary, no significant adverse events have been documented in people being treated with melatonin at a dose of $5 \mathrm{mg}$ chronically. The only potential adverse effects of melatonin administration are related to reproductive function (82). Arendt pointed to negative consequences for the circulatory system, including clotting, but did not specify them. Abdominal pain was observed following the administration of extremely high dosages of melatonin (50 mg - $6.6 \mathrm{~g}$ ) (83). Melatonin was found to have antigonadal properties in postmenopausal women and to decrease ovarian activity in cycling women utilizing 75 - 300 mg of melatonin per day (84). Melatonin treatment of insomniac children and the elderly was generally well tolerated. However, precautions should be taken when prolonged melatonin use is needed, as potential adverse effects have not been adequately explored.

\section{Conclusions}

Exogenous melatonin possesses pronounced chronobiotic, antioxidant, antiadrenergic, and hypothermic properties. We believe that acute melatonin ingestion at the beginning of exercise may improve cardiovascular 
function during prolonged submaximal exercise by restoring an "optimal" redox balance. Therefore, we highlight that the dose and the time of melatonin administration must be carefully selected and based on expert knowledge:

Generally, a high dose of antioxidants has no beneficial effect on healthy humans. A high dose of antioxidants may have pro-oxidant activities by disrupting the redox balance. Melatonin supplementation at high doses causes bradycardia during exercise and may have a negative impact on cardiovascular and renal function and thermoregulatory control by lowering free radicals and catecholamine production at the beginning of exercise. Generally, the adverse events associated with melatonin administration were short-lived and associated with daytime dosing. Therefore, melatonin should be administered at night when possible.

Interestingly, exogenous melatonin intake before endurance exercise could also be used as an effective strategy to promote fat-burning, which means that melatonin could be a novel strategy for weight loss. Therefore, this article is also a call for action for researchers to consider testing these potential paths towards promoting weight loss through melatonin supplementation or by practicing endurance exercise in the early morning when endogenous melatonin levels are slightly high.

\section{Acknowledgments}

No external funding related to the project has been received.

\section{Footnotes}

Authors' Contribution: Both authors contributed equally to the whole manuscript.

Conflict of Interests: No conflict of interest to disclose.

Data Reproducibility: All data analysed and reported in this study are available from the first author on reasonable request.

Funding/Support: This research received no specific grant from any funding agency in the public, commercial or not-for-profit sectors.

\section{References}

1. Cagnacci A, Elliott JA, Yen SS. Melatonin: a major regulator of the circadian rhythm of core temperature in humans. J Clin Endocrinol Metab. 1992;75(2):447-52. doi: 10.1210/jcem.75.2.1639946. [PubMed:1639946].

2. Mhenni T, Souissi A, Tayech A, Yousfi N, Mejri MA, Chamari K, et al. The effect of Ramadan fasting on the morning-evening difference in team-handball-related short-term maximal physical performances in elite female team-handball players. Chronobiol Int. 2021;38(10):1-12. doi: 10.1080/07420528.2021.1932994. [PubMed:34112026].
3. Waterhouse J, Drust B, Weinert D, Edwards B, Gregson W, Atkinson G, et al. The circadian rhythm of core temperature: origin and some implications for exercise performance. Chronobiol Int. 2005;22(2):20725. doi: 10.1081/cbi-200053477. [PubMed: 16021839].

4. Dergaa I, Varma A, Musa S, Chaabane M, Ben Salem A, Fessi MS. Diurnal Variation: Does It Affect Short-term Maximal Performance and Biological Parameters in Police Officers? Int J Sport Stud Helath. 2020;3(2). doi: 10.5812/intjsh.111424.

5. Souissi A, Yousfi N, Souissi N, Haddad M, Driss T. The effect of diurnal variation on the performance of exhaustive continuous and alternated-intensity cycling exercises. PLoS One. 2020;15(12). e0244191. doi: 10.1371/journal.pone.0244191. [PubMed: 33382736]. [PubMed Central: PMC7775070].

6. Dergaa I, Ben Saad H, Romdhani M, Souissi A, Fessi MS, Yousfi N, et al. Biological Responses to Short-Term Maximal Exercise in Male Police Officers. Am J Mens Health. 2021;15(4):15579883211040900. doi: 10.1177/15579883211040920. [PubMed: 34414822]. [PubMed Central: PMC8381431].

7. Dergaa I, Romdhani M, Fessi MS, Ben Saad H, Varma A, Ben Salem A, et al. Does lunar cycle affect biological parameters in young healthy men? Chronobiol Int. 2021;38(6):1-8. doi: 10.1080/07420528.2021.1897609. [PubMed: 33779457].

8. Dergaa I, Fessi MS, Chaabane M, Souissi N, Hammouda O. The effects of lunar cycle on the diurnal variations of short-term maximal performance, mood state, and perceived exertion. Chronobiol Int. 2019;36(9):1249-57. doi: 10.1080/07420528.2019.1637346. [PubMed: 31368366].

9. Tan DX, Manchester LC, Reiter RJ, Qi WB, Karbownik M, Calvo JR. Significance of melatonin in antioxidative defense system: reactions and products. Biol Signals Recept. 2000;9(3-4):137-59. doi: 10.1159/000014635. [PubMed: 10899700].

10. Brzezinski A. Melatonin in humans. N Engl J Med. 1997;336(3):186-95. doi: 10.1056/NEJM199701163360306. [PubMed: 8988899].

11. Hacıșevki A, Baba B. An Overview of Melatonin as an Antioxidant Molecule: A Biochemical Approach. Melatonin: Molecular Biology, Clinical and Pharmaceutical Approaches. IntechOpen; 2018. p. 59-85. doi: 10.5772/intechopen.79421.

12. Aly HF, Rizk MZ. Melatonin and Its Indisputable Effects on the Health State. Melatonin-Molecular Biology, Clinical and Pharmaceutical Approaches. IntechOpen; 2018.

13. Reiter RJ, Tan DX, Paredes SD, Fuentes-Broto L. Beneficial effects of melatonin in cardiovascular disease. Ann Med.2010;42(4):276-85. doi: 10.3109/07853890903485748. [PubMed: 20455793].

14. Costello RB, Lentino CV, Boyd CC, O'Connell ML, Crawford CC, Sprengel ML, et al. The effectiveness of melatonin for promoting healthy sleep: a rapid evidence assessment of the literature. Nutr J. 2014;13:117. doi:10.1186/1475-2891-13-106. [PubMed: 25380732]. [PubMed Central: PMC4273450].

15. Sun C, Wu Q, Rong B. Melatonin: A novel strategy for prevention of obesity and fat accumulation in peripheral organs through the improvements of circadian rhythms and antioxidative capacity. Melatonin Res. 2020;3(1):58-76. doi: 10.32794/mr11250048.

16. Dawson D, Encel N. Melatonin and sleep in humans. $J$ Pineal Res. 1993;15(1):1-12. doi: 10.1111/j.1600-079x.1993.tb00503.x. [PubMed: 8229640].

17. Brzezinski A, Vangel MG, Wurtman RJ, Norrie G, Zhdanova I, Ben-Shushan A, et al. Effects of exogenous melatonin on sleep: a meta-analysis. Sleep Med Rev. 2005;9(1):41-50. doi: 10.1016/j.smrv.2004.06.004. [PubMed: 15649737].

18. Ochoa JJ, Diaz-Castro J, Kajarabille N, Garcia C, Guisado IM, De Teresa C, et al. Melatonin supplementation ameliorates oxidative stress and inflammatory signaling induced by strenuous exercise in adult human males. J Pineal Res. 2011;51(4):373-80. doi: 10.1111/j.1600079X.2011.00899.x. [PubMed: 21615492]. 
19. Leonardo-Mendonca RC, Ocana-Wilhelmi J, de Haro T, de TeresaGalvan C, Guerra-Hernandez E, Rusanova I, et al. The benefit of a supplement with the antioxidant melatonin on redox status and muscle damage in resistance-trained athletes. Appl Physiol Nutr Metab. 2017;42(7):700-7. doi: 10.1139/apnm-2016-0677. [PubMed: 28192673].

20. Escames G, Ozturk G, Bano-Otalora B, Pozo MJ, Madrid JA, Reiter RJ, et al. Exercise and melatonin in humans: reciprocal benefits. J Pineal Res. 2012;52(1):1-11. doi: 10.1111/j.1600-079X.2011.00924.x. [PubMed: 21848991].

21. Michailidis Y, Jamurtas AZ, Nikolaidis MG, Fatouros IG, Koutedakis Y, Papassotiriou I, et al. Sampling time is crucial for measurement of aerobic exercise-induced oxidative stress. Med Sci Sports Exerc. 2007;39(7):1107-13. doi: 10.1249/01.mss.ob013e318053e7ba. [PubMed: 17596778].

22. Coombes JS, Rowell B, Dodd SL, Demirel HA, Naito H, Shanely RA, et al. Effects of vitamin E deficiency on fatigue and muscle contractile properties. Eur J Appl Physiol. 2002;87(3):272-7. doi: 10.1007/s00421002-0631-3. [PubMed: 12111289].

23. Kruk J, Aboul-Enein BH, Duchnik E. Exercise-induced oxidative stress and melatonin supplementation: current evidence. J Physiol Sci. 2021;71(1):1-19. doi: 10.1186/s12576-021-00812-2. [PubMed: 34470608]. [PubMed Central: PMC8409271]

24. Liesa M, Shirihai OS. Mitochondrial dynamics in the regulation of nutrient utilization and energy expenditure. Cell Metab. 2013;17(4):491506. doi: 10.1016/j.cmet.2013.03.002. [PubMed: 23562075]. [PubMed Central: PMC5967396].

25. Borges Lda S, Dermargos A, da Silva Junior EP, Weimann E, Lambertucci RH, Hatanaka E. Melatonin decreases muscular oxidative stress and inflammation induced by strenuous exercise and stimulates growth factor synthesis. J Pineal Res. 2015;58(2):166-72. doi: 10.1111/jpi.12202. [PubMed: 25546615].

26. Trionfante CP, Davis GR, Farney TM, Miskowiec RW, Nelson AG. A preexercise dose of melatonin can alter substrate use during exercise. Int J Exerc Sci. 2017;10(7):1029.

27. Czuczejko J, Sielski L, Wozniak B, Wozniak A, Szewczyk-Golec K. Melatonin supplementation improves oxidative and inflammatory state in the blood of professional athletes during the preparatory period for competitions. Free Radic Res. 2019;53(2):198-209. doi: 10.1080/10715762.2018.1563688. [PubMed:30646765].

28. Farjallah MA, Hammouda O, Ben Mahmoud L, Graja A, Ghattassi K, Boudaya $\mathrm{M}$, et al. Melatonin supplementation ameliorates oxidative stress, antioxidant status and physical performances recovery during a soccer training camp. Biol Rhythm Res. 2020;51(3):441-52. doi: 10.1080/09291016.2018.1533749.

29. Ortiz-Franco M, Planells E, Quintero B, Acuna-Castroviejo D, Rusanova I, Escames G, et al. Effect of Melatonin Supplementation on Antioxidant Status and DNA Damage in High Intensity Trained Athletes. Int J Sports Med. 2017;38(14):1117-25. doi: 10.1055/s-0043-119881. [PubMed: 29165732].

30. López-Flores M, Luque-Nieto R, Costa Moreira O, Suárez-Iglesias D, Villa-Vicente JG. Effects of Melatonin on Sports Performance: A Systematic Review. J Exerc Physiol Online. 2018;21(5).

31. Edwards BJ, Atkinson G, Waterhouse J, Reilly T, Godfrey R, Budgett $\mathrm{R}$. Use of melatonin in recovery from jet-lag following an eastward flight across 10 time-zones. Ergonomics. 2000;43(10):1501-13. doi: 10.1080/001401300750003934. [PubMed: 11083131].

32. Ghattassi K, Hammouda O, Graja A, Boudhina N, Chtourou H, Hadhri $S$, et al. Morning melatonin ingestion and diurnal variation of short-term maximal performances in soccer players. Physiol Int. 2016;103(1):94-104. doi: 10.1556/036.103.2016.1.9. [PubMed: 27030631].

33. Konarska A, Karolkiewicz J, Kasprzak Z, Pilaczyńska-Szcześniak Ł. CHANGES IN MELATONIN CONCENTRATION AFTER PHYSICAL EXERCISE OF VARIABLE INTENSITY. Stud Phys Cult Tour. 2006;13(2).

34. Tzischinsky O, Lavie P. Melatonin possesses time-dependent hypnotic effects. Sleep. 1994;17(7):638-45. doi: 10.1093/sleep/17.7.638. [PubMed: 7846463].
35. Dollins AB, Zhdanova IV, Wurtman RJ, Lynch HJ, Deng MH. Effect of inducing nocturnal serum melatonin concentrations in daytime on sleep, mood, body temperature, and performance. Proc Natl Acad Sci USA. 1994;91(5):1824-8. doi: 10.1073/pnas.91.5.1824. [PubMed: 8127888]. [PubMed Central: PMC43256].

36. Samuels $\mathrm{CH}$. Jet lag and travel fatigue: a comprehensive management plan for sport medicine physicians and highperformance support teams. Clin J Sport Med. 2012;22(3):268-73. doi: 10.1097/JSM.0b013e31824d2eeb. [PubMed: 22450594].

37. Souissi A, Yousfi N, Dabboubi R, Aloui G, Haddad M, Souissi N. Effect of acute melatonin administration on physiological response to prolonged exercise. Biol Rhythm Res. 2019;51(6):980-7. doi: 10.1080/09291016.2019.1573462.

38. Waterhouse J, Atkinson G. Melatonin as an ergogenic aid. Biol Rhythm Res. 2009;40(1):71-9. doi: 10.1080/09291010802067106.

39. Gonzalez-Alonso J, Teller C, Andersen SL, Jensen FB, Hyldig T, Nielsen B. Influence of body temperature on the development of fatigue during prolonged exercise in the heat. J Appl Physiol (1985).1999;86(3):1032-9. doi: 10.1152/jappl.1999.86.3.1032. [PubMed:10066720].

40. Walters TJ, Ryan KL, Tate LM, Mason PA. Exercise in the heat is limited by a critical internal temperature. J Appl Physiol (1985). 2000;89(2). doi: 10.1152/jappl.2000.89.2.799. [PubMed:10926668].

41. Souissi A, Dergaa I, Musa S, Ben Saad H, Souissi N. Effects of daytime ingestion of melatonin on heart rate response during prolonged exercise. Mov Sports Sci. 2021;(115). doi: 10.1051/sm/2021020.

42. Marrin K, Drust B, Gregson W, Atkinson G. A meta-analytic approach to quantify the dose-response relationship between melatonin and core temperature. Eur J Appl Physiol. 2013;113(9):2323-9. doi: 10.1007/s00421-013-2668-x. [PubMed: 23771573].

43. McLellan TM, Smith IF, Gannon GA, Zamecnik J. Melatonin has no effect on tolerance to uncompensable heat stress in man. Eur J Appl Physiol. 2000;83(4 -5):336-43. doi: 10.1007/s004210000291. [PubMed: 11138572].

44. Brandenberger KJ, Ingalls $\mathrm{CP}$, Rupp JC, Doyle JA. Consumption of a 5-mg Melatonin Supplement Does Not Affect 32.2-km Cycling Time Trial Performance. J Strength Cond Res. 2018;32(10):2872-7. doi: 10.1519/JSC.0000000000001955. [PubMed: 28557857].

45. Souissi A, Souissi N, Dabboubi R, Souissi N. Effect of melatonin on inflammatory response to prolonged exercise. Biol Rhythm Res. 2018;51(4):560-5. doi: 10.1080/09291016.2018.1543638.

46. Souissi A, Yousfi N, Rouissi M, Messaoud T, Souissi N, Abderrahmen $\mathrm{AB}$, et al. Does Melatonin Supplementation Affect Renal Function in Healthy Humans during Prolonged Exercise? Swed J Sci Res.

47. Amano T, Fujii N, Louie JC, Meade RD, Kenny GP. Individual variations in nitric oxide synthase-dependent sweating in young and older males during exercise in the heat: role of aerobic power. Physiol Rep. 2017;5(6). doi: 10.14814/phy2.13208. [PubMed: 28325791]. [PubMed Central: PMC5371569].

48. Nishiyama K, Yasue H, Moriyama Y, Tsunoda R, Ogawa H, Yoshimura $\mathrm{M}$, et al. Acute effects of melatonin administration on cardiovascular autonomic regulation in healthy men. Am Heart J. 2001;141(5):13-7. doi: 10.1067/mhj.2001.114368. [PubMed: 11320384].

49. Sewerynek E. Melatonin and the cardiovascular system. Neuro Endocrinol Lett. 2002;23:79-83.

50. Silva CL, Tamura EK, Macedo SM, Cecon E, Bueno-Alves L, Farsky SH et al. Melatonin inhibits nitric oxide production by microvascular endothelial cells in vivo and in vitro. Br J Pharmacol. 2007;151(2):195205. doi: 10.1038/sj.bjp.0707225. [PubMed: 17375079]. [PubMed Central: PMC2013957].

51. Tamura EK, Silva CL, Markus RP. Melatonin inhibits endothelial nitric oxide production in vitro. J Pineal Res. 2006;41(3):267-74. doi 10.1111/j.1600-079X.2006.00366.x. [PubMed: 16948788].

52. Cook JS, Sauder CL, Ray CA. Melatonin differentially affects vascular blood flow in humans. Am J Physiol Heart Circ Physiol. 2011;300(2):H670-4. doi: 10.1152/ajpheart.00710.2010. [PubMed: 
21148765]. [PubMed Central: PMC3044053].

53. Aydogdu N, Erbas H, Atmaca G, Erten O, Kaymak K. Melatonin reduces nitric oxide via increasing arginase in rhabdomyolysisinduced acute renal failure in rats. Ren Fail. 2006;28(5):435-40. doi: 10.1080/08860220600683631. [PubMed:16825094].

54. Trinity JD, Broxterman RM, Richardson RS. Regulation of exercise blood flow: Role of free radicals. Free Radic Biol Med. 2016;98:90102. doi: 10.1016/j.freeradbiomed.2016.01.017. [PubMed: 26876648] [PubMed Central: PMC4975999].

55. Donato AJ, Uberoi A, Bailey DM, Wray DW, Richardson RS. Exerciseinduced brachial artery vasodilation: effects of antioxidants and exercise training in elderly men. Am J Physiol Heart Circ Physiol. 2010;298(2):H671-8. doi: 10.1152/ajpheart.00761.2009. [PubMed: 19966056]. [PubMed Central: PMC2822587].

56. Richardson RS, Donato AJ, Uberoi A, Wray DW, Lawrenson L, Nishiyama S, et al. Exercise-induced brachial artery vasodilation: role of free radicals. Am J Physiol Heart Circ Physiol. 2007;292(3):H1516-22. doi: 10.1152/ajpheart.01045.2006. [PubMed: 17114239].

57. Hardeland R, Coto-Montes A, Poeggeler B. Circadian rhythms, oxidative stress, and antioxidative defense mechanisms. Chronobiol Int 2003;20(6):921-62. doi: 10.1081/cbi-120025245. [PubMed:14680136].

58. Souissi A, Haddad M, Dergaa I, Ben Saad H, Chamari K. A new perspective on cardiovascular drift during prolonged exercise. Life Sci. 2021;287:120109. doi: 10.1016/j.lfs.2021.120109. [PubMed: 34717912]

59. Kojda G, Hambrecht R. Molecular mechanisms of vascular adaptations to exercise. Physical activity as an effective antioxidant therapy? Cardiovasc Res. 2005;67(2):187-97. doi: 10.1016/j.cardiores.2005.04.032. [PubMed: 15935334].

60. Laurindo FR, Pedro Mde A, Barbeiro HV, Pileggi F, Carvalho MH, Augusto $\mathrm{O}$, et al. Vascular free radical release. Ex vivo and in vivo evidence for a flow-dependent endothelial mechanism. Circ Res. 1994;74(4):700-9. doi:10.1161/01.res.74.4.700. [PubMed: 7511072].

61. Lauer N, Suvorava T, Ruther U, Jacob R, Meyer W, Harrison DG, et al. Critical involvement of hydrogen peroxide in exerciseinduced up-regulation of endothelial NO synthase. Cardiovasc Res. 2005;65(1):254-62. doi: 10.1016/j.cardiores.2004.09.010. [PubMed: 15621054].

62. Powers SK, Nelson WB, Hudson MB. Exercise-induced oxidative stress in humans: cause and consequences. Free Radic Biol Med. 2011;51(5):942-50. doi: 10.1016/j.freeradbiomed.2010.12.009. [PubMed: 21167935].

63. Kawamura T, Fujii R, Li X, Higashida K, Muraoka I. Effects of exhaustive exercises, with different intensities, on oxidative stress markers in rat plasma and skeletal muscle. Sci Sports. 2018;33(3):169-75. doi: 10.1016/j.scispo.2017.08.008.

64. Manning RJ, Meng S, Tian N. Renal and vascular oxidative stress and salt-sensitivity of arterial pressure. Acta Physiol Scand. 2003;179(3):243-50. doi: 10.1046/j.0001-6772.2003.01204.x. [PubMed: 14616240].

65. Kouti L, Sayyah M, Mosallanezhad P, Kooti S, Aghakoochakzadeh M, Eslami K. Changes of Nitric Oxide and Peroxynitrite Serum Levels during Drug Therapy in Patients with Obsessive-Compulsive Disorder. Adv Med. 2016;2016:9131680. doi: 10.1155/2016/9131680. [PubMed: 27822492]. [PubMed Central: PMC5086350].

66. Souissi A, Dergaa I, Chtourou H, Ben Saad H. The Effect of Daytime Ingestion of Melatonin on Thyroid Hormones Responses to Acute Submaximal Exercise in Healthy Active Males: A Pilot Study. Am J Mens Health. 2022;16(1):15579883211070400. doi: 10.1177/15579883211070383. [PubMed: 35060417]. [PubMed Central: PMC8785310].

67. Ghattassi K, Graja A, Hammouda O, Chtourou H, Boudhina N, Chaouachi A, et al. Effect of nocturnal melatonin ingestion on shortterm anaerobic performance in soccer players. Biol Rhythm Res. 2014;45(6):885-93. doi: 10.1080/09291016.2014.929853.
68. Arangino S, Cagnacci A, Angiolucci M, Vacca AM, Longu G, Volpe A, et al. Effects of melatonin on vascular reactivity, catecholamine levels, and blood pressure in healthy men. Am J Card. 1999;83(9):1417-9. doi: 10.1016/s0002-9149(99)00112-5.

69. Cagnacci A, Arangino S, Angiolucci M, Maschio E, Melis GB. Influences of melatonin administration on the circulation of women. Am JPhysiol. 1998;274(2):R335-8. doi: 10.1152/ajpregu.1998.274.2.R335. [PubMed: 9486289].

70. Doolen S, Krause DN, Dubocovich ML, Duckles SP. Melatonin mediates two distinct responses in vascular smooth muscle. Eur J Pharmacol. 1998;345(1):67-9. doi:10.1016/s0014-2999(98)00064-8.

71. Ting N, Thambyraja A, Sugden D, Scalbert E, Delagrange P, Wilson VG. Pharmacological studies on the inhibitory action of melatonin and putative melatonin analogues on porcine vascular smooth muscle. Naunyn Schmiedebergs Arch Pharmacol. 2000;361(3):327-33. doi: 10.1007/s002109900198. [PubMed:10731047].

72. Niijima A, Chun S, Shima T, Bizot-Espiard J, Guardiola-Lemaitre B, Nagai K. Effect of intravenous administration of melatonin on the efferent activity of the adrenal nerve. J Auton Nerv Sys. 1998;71(2-3):134-8. doi: 10.1016/s0165-1838(98)00067-8.

73. Forsling ML, Wheeler MJ, Williams AJ. The effect of melatonin administration on pituitary hormone secretion in man. Clin Endocrinol (Oxf). 1999;51(5):637-42. doi: 10.1046/j.1365-2265.1999.00820.x. [PubMed: 10594526].

74. Lieberman HR, Waldhauser F, Garfield G, Lynch HJ, Wurtman RJ. Effects of melatonin on human mood and performance. Brain Res. 1984;323(2):201-7. doi:10.1016/0006-8993(84)90290-7.

75. Rogers NL, Phan O, Kennaway DJ, Dawson D. Effect of daytime oral melatonin administration on neurobehavioral performance in humans. J Pineal Res. 1998;25(1):47-53. doi: 10.1111/j.1600079x.1998.tb00385.x. [PubMed: 9694404].

76. Suhner A, Schlagenhauf P, Tschopp A, Hauri-Bionda R, Friedrich-Koch A, Steffen R. Impact of melatonin on driving performance. J Travel Med. 1998;5(1):7-13. doi: 10.1111/j.1708-8305.1998.tb00448.x. [PubMed: 9772309].

77. Rogers NL, Kennaway DJ, Dawson D. Neurobehavioural performance effects of daytime melatonin and temazepam administration. $J$ Sleep Res. 2003;12(3):207-12. doi: 10.1046/j.1365-2869.2003.00360.x. [PubMed: 12941059].

78. Sherer MA, Weingartner H, James SP, Rosenthal NE. Effects of melatonin on performance testing in patients with seasonal affective disorder. Neuro Endocrinol Lett. 1985;58(3):277-82. doi: 10.1016/03043940(85)90066-7.

79. Zhdanova IV, Lynch HJ, Wurtman RJ. Melatonin: a sleep-promoting hormone. Sleep. 1997;20(10):899-907.

80. Lewy AJ, Bauer VK, Ahmed S, Thomas KH, Cutler NL, Singer CM, et al. The human phase response curve (PRC) to melatonin is about 12 hours out of phase with the PRC to light. Chronobiol Int.1998;15(1):7183. doi: 10.3109/07420529808998671. [PubMed: 9493716].

81. Auld F, Maschauer EL, Morrison I, Skene DJ, Riha RL. Evidence for the efficacy of melatonin in the treatment of primary adult sleep disorders. Sleep Med Rev.2017;34:10-22. doi:10.1016/j.smrv.2016.06.005. [PubMed: 28648359].

82. Wright J, Aldhous M, Franey C, English J, Arendt J. The effects of exogenous melatonin on endocrine function in man. Clin Endocrinol (Oxf).1986;24(4):375-82. doi:10.1111/j.1365-2265.1986.tb01641.x. [PubMed: 3742833].

83. Arendt J. Melatonin and the mammalian pineal gland. Springer Science \& Business Media; 1994.

84. Voordouw BC, Euser R, Verdonk RE, Alberda BT, de Jong FH, Drogendijk AC, et al. Melatonin and melatonin-progestin combinations alter pituitary-ovarian function in women and can inhibit ovulation. JClin Endocrinol Metab.1992;74(1):108-17. doi:10.1210/jcem.74.1.1727807. 